Check for updates

Cite this: RSC Adv., 2019, 9, 307

Received 19th July 2018

Accepted 10th December 2018

DOI: $10.1039 / c 8 \mathrm{ra06112b}$

rsc.li/rsc-advances

\section{A novel 3D Cd(II) coordination polymer generated via in situ ligand synthesis involving $\mathrm{C}-\mathrm{O}$ ester bond formation $\uparrow$}

\author{
Ji-Jiang Wang, (D) * Zhuang Cao, (D) Xiao Wang, (D) Long Tang, (D) Xiang-Yang Hou, \\ Ping Ju, (iD) Yi-Xia Ren, (D) Xiao-Li Chen (D) and Yu-Qi Zhang (D)
}

A novel 3D $\mathrm{Cd}(॥)$ coordination polymer $\left\{\left[\mathrm{Cd}(\mathrm{ddpa})\left(2,2^{\prime}-\mathrm{bpy}\right)\right] \cdot \mathrm{H}_{2} \mathrm{O}\right\}_{n}$ (1) $\left(\mathrm{H}_{2}\right.$ ddpa $=5,10$-dioxo-5,10dihydro-4,9-dioxapyrene-2,7-dicarboxylic acid, 2,2'-bpy =2,2'-bipyridine) is hydrothermally synthesized in situ, and the influencing factors and mechanism for the in situ reaction are briefly discussed. The synthesis of 1 requires the formation of a new $\mathrm{C}-\mathrm{O}$ ester bond. This current study confirms that metal ions and $\mathrm{N}$-donor ligands play important roles in the domination of the in situ ligand from 6,6'-dinitro2,2',4,4'-biphenyltetracarboxylic acid $\left(\mathrm{H}_{4} \mathrm{dbta}\right)$. Furthermore, the structure, thermal stability and photoluminescent property of 1 are also investigated.

\section{Introduction}

Hydro(solvo)thermal in situ ligand syntheses are of great interest in coordination chemistry and organic chemistry for the preparation of unusual coordination compounds, discovery of new organic reactions and understanding their mechanisms. ${ }^{1-5}$ So far, a variety of in situ ligand syntheses have already been reported, which include the formation of $\mathrm{C}-\mathrm{C}, \mathrm{C}-\mathrm{N}, \mathrm{S}-\mathrm{S}$, $\mathrm{C}-\mathrm{O},-\mathrm{O}-$, and $\mathrm{C}=\mathrm{C}$ bonds, ${ }^{6-11}$ oxidation of a phenyl ring with a methyl group, ${ }^{12}$ formation of tetrazole, ${ }^{13-15}$ and decarboxylation of aromatic carboxylates. ${ }^{16}$ Since the hydro(solvo)thermal reaction is affected by several factors such as solvents, temperature, metal ions, organic ligands and anions, ${ }^{\mathbf{1 7 - 2 4}}$ it is still a formidable challenge to elucidate the reaction mechanism of in situ ligand syntheses.

It is well-known that the rational design and reasonable use of the organic multicarboxylate ligands are very important in the construction of desired coordination polymers. Although many studies have recently focused on the use of biphenyl$2,2^{\prime}, 4,4^{\prime}$-tetracarboxylic acid, ${ }^{25-35}$ the use of $6,6^{\prime}$-dinitro- $2,2^{\prime}, 4,4^{\prime}$ biphenyltetracarboxylic acid $\left(\mathrm{H}_{4} \mathrm{dbta}\right)$ has not been adequately explored. ${ }^{36-38}$ Compared with biphenyl-2,2',4,4'-tetracarboxylic acid, although the nitro groups of $\mathrm{H}_{4} \mathrm{dbta}$ might be unlikely to form coordination bonds with metal ions, they can influence

Yan'an University Key Laboratory of New Energy \& New Function Materials, Shaanxi Key Laboratory of Chemical Reaction Engineering, College of Chemistry and Chemical Engineering, Yan'an University, Yan'an 716000, P. R. China. E-mail: yadxwjj@126. com

† Electronic supplementary information (ESI) available: Bond length/angle tables, figure of single-crystal, additional PXRD patterns, FT-IR, TGA. CCDC 1840510-1840512 for 1-3. For ESI and crystallographic data in CIF or other electronic format see DOI: 10.1039/c8ra06112b the coordination and framework due to their electronegative and steric effects. ${ }^{39}$

Prior to this study, we reported the synthesis of a 3D pillared bilayer $\mathrm{Cd}(\mathrm{II})$ coordination polymer based on $\mathrm{H}_{4} \mathrm{dbta}\left\{\left[\mathrm{Cd}_{2}(-\right.\right.$ dbta $)(\mathrm{dpe})]_{n}, \quad \mathrm{H}_{4}$ dbta $=6,6^{\prime}$-dinitro-2,2',4,4'-biphenyltetracarboxylic acid, dpe $=1,2-\operatorname{di}\left(4\right.$-pyridyl)ethylene.$^{40}$ In a follow-up study, we found that the replacement of 1,2-di (4pyridyl) ethylene (dpe) with $2,2^{\prime}$-bipyridine (2,2'-bpy) resulted in an in situ reaction containing a $\mathrm{C}-\mathrm{O}$ ester bond in $\mathrm{H}_{4} \mathrm{dbta}$ molecule to form the $\mathrm{ddpa}^{2-}$ ligand $\left(\mathrm{ddpa}^{2-}=5,10\right.$-dioxo-5,10dihydro-4,9-dioxapyrene-2,7-dicarboxylate; its ring system is identical to that of the natural tetracyclic diester ellagic acid), which resulted in the synthesis of another three-dimensional (3D) coordination polymer $\left\{\left[\mathrm{Cd}(\mathrm{ddpa})\left(2,2^{\prime}-\mathrm{bpy}\right)\right] \cdot \mathrm{H}_{2} \mathrm{O}\right\}_{n} \quad$ (1). Although two coordination polymers of the $\mathrm{ddpa}^{2-}$ ligand have been reported by Cheetham and Huang groups, ${ }^{41,42}$ the synthesis of the ddpa ${ }^{2-}$ ligand includes the in situ reaction of 5hydroxyisophthalic acid $\left(\mathrm{OH}-\mathrm{H}_{2} \mathrm{BDC}\right)$ and $\mathrm{Ni}(\mathrm{II}) / \mathrm{Ce}(\mathrm{III})$ ions (Scheme 1). In this in situ synthesis, the formation of the $\mathrm{C}-\mathrm{O}$ ester bond belongs to conventional esterifications, in which at least one $-\mathrm{OH}$ (hydroxyl) group of the carboxylic acids is replaced with an -O-alkyl (alkoxy) group. The most important difference between our work and the study reported by Cheetham and Huang groups is that we obtained the ddpa ${ }^{2-}$ ligand by the in situ ligand synthesis of $\mathrm{H}_{4} \mathrm{dbta}, \mathrm{Cd}(\mathrm{II})$ and 2,2'-bpy (Scheme 2). Thus, it is necessary to explore the influencing factors for the in situ reaction of $\mathrm{H}_{4} \mathrm{dbta}$.

In this paper, the influencing factors and mechanism for the in situ generation of $\mathbf{1}$ are also briefly discussed. It is interesting that this in situ reaction is only observed when the metal ions and $\mathrm{N}$-donor ligands are $\mathrm{Cd}(\mathrm{II})$ and 2,2'-bpy, respectively. If $\mathrm{Cd}(\mathrm{II})$ and 1,10-phenanthroline (phen)/dpe are used, 1D/3D structures of $\left\{\left[\mathrm{Cd}_{2}(\mathrm{dbta}) \text { (phen) }{ }_{2}\left(\mathrm{H}_{2} \mathrm{O}\right)\right] \cdot \mathrm{H}_{2} \mathrm{O}\right\}_{n}(2)$ and $\left[\mathrm{Cd}_{2}\right.$ 


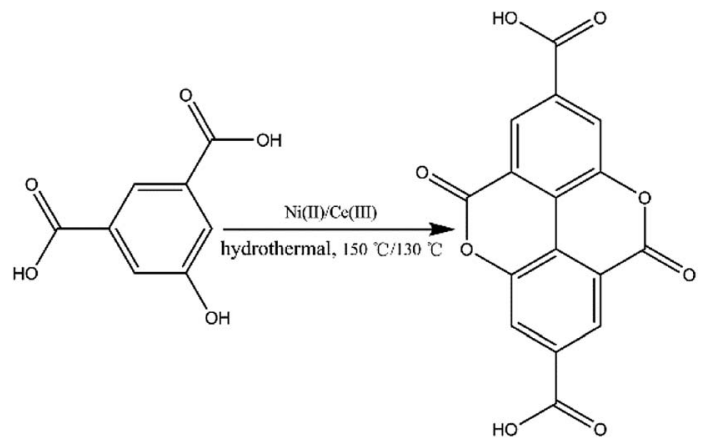

Scheme 1 In situ synthesis of the $\mathrm{H}_{2}$ ddpa ligand from $\mathrm{OH}-\mathrm{H}_{2}$ bdc.

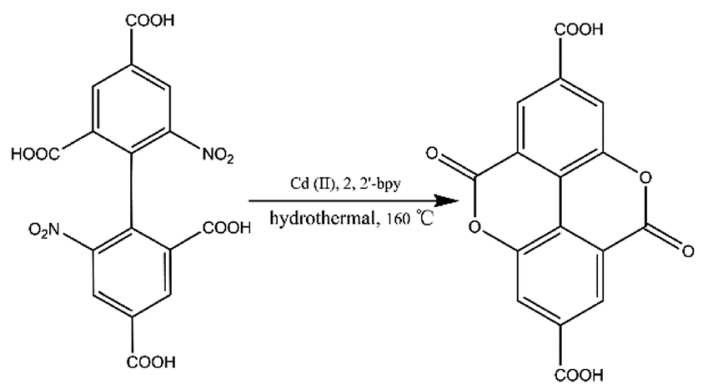

Scheme 2 In situ synthesis of the $\mathrm{H}_{2}$ ddpa ligand from $\mathrm{H}_{4} \mathrm{dbta}$.

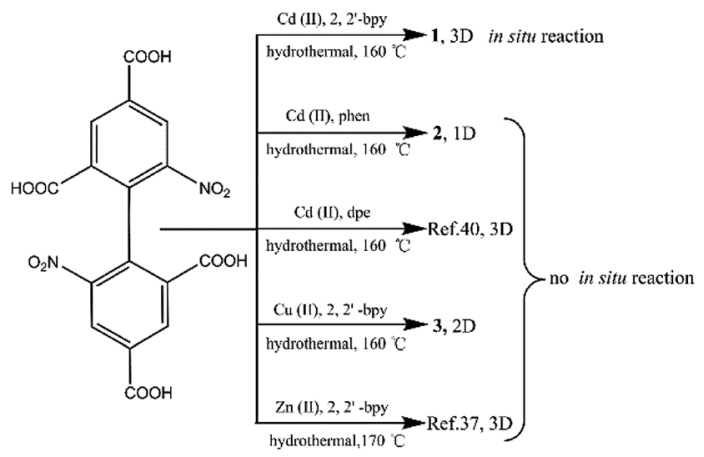

Scheme 3 The synthetic route for compounds $1-3,\left[\mathrm{Cd}_{2}(\mathrm{dbta})(\mathrm{dpe})\right]_{n}$ (ref. 40) and $\left[\mathrm{Zn}_{2}\right.$ (dbta) $\left(2,2^{\prime}-\text { bpy) }\right]_{n}$ (ref. 37).

(dbta) (dpe) $]_{n}{ }^{40}$ are obtained by the hydrothermal reaction. In addition, the replacement of $\mathrm{Cd}(\mathrm{II})$ ions in 1 with $\mathrm{Cu}(\mathrm{II}) / \mathrm{Zn}(\mathrm{II})$ results in two different $2 \mathrm{D} / 3 \mathrm{D}$ structures of $\left\{\left[\mathrm{Cu}_{2}\right.\right.$ (dbta) $\left(2,2^{\prime}\right.$ bpy $\left.\left.)_{2}\right] \cdot \mathrm{H}_{2} \mathrm{O}\right\}_{n}$ (3) and $\left[\mathrm{Zn}_{2}\right.$ (dbta) $\left(2,2^{\prime} \text {-bpy) }\right]_{n}{ }^{37}$ (Scheme 3). As far as we know, this is the first example of a coordination polymer obtained via in situ synthesis of the $\mathrm{H}_{4} \mathrm{dbta}$ ligand. Our study suggests that the synergetic effects of both $2,2^{\prime}$-bpy and Cd(II) ions are important factors in controlling the formation of the $\mathrm{ddpa}^{2-}$ ligand. In this in situ synthesis, the formation of the $\mathrm{C}-\mathrm{O}$ ester bond was not by conventional esterifications, which expands the conception of esterifications in organic chemistry. The result provides a promising route to design and construct a new organic ligand with special structures and properties. Furthermore, the thermal stability and photoluminescent properties of 1-3 are also investigated.

\section{Experimental}

\subsection{Materials and methods}

All reagents and solvents employed were commercially available and used without further purification. The $\mathrm{C}, \mathrm{H}$ and $\mathrm{N}$ microanalyses were carried out with a PE 2400 Series II elemental analyzer. The IR spectra were recorded with a Shimadzu IR Affinity-1 spectrometer using the $\mathrm{KBr}$ pellet technique. Thermogravimetric analysis was performed on a NETZSCH STA $449 \mathrm{~F} 3$ analyzer. The powder X-ray diffraction (PXRD) measurement was carried out using a Shimadzu XRD-7000 diffractometer with $\mathrm{Cu} \mathrm{K} \alpha$ radiation $(\lambda=1.5418 \AA)$. Photoluminescence spectra were obtained on a Hitachi F-4500 fluorescence spectrophotometer at room temperature.

\subsection{Synthetic procedures}

2.2.1 Synthesis of $\left\{\left[\mathrm{Cd} \text { (ddpa) }\left(2,2^{\prime}-\text { bpy }\right)\right] \cdot \mathrm{H}_{2} \mathrm{O}\right\}_{n}$ (1). A mixture of CdO $(0.0064 \mathrm{~g}, 0.05 \mathrm{mmol}), \mathrm{H}_{4} \mathrm{dbta}(0.0210 \mathrm{~g}, 0.05$ mmol), 2,2'-bpy (0.0078 g, $0.05 \mathrm{mmol})$ and $10 \mathrm{~mL} \mathrm{H}_{2} \mathrm{O}$ was stirred for $30 \mathrm{~min}$. The mixture was then placed in a $25 \mathrm{~mL}$ Teflon-lined stainless steel vessel and heated at $160{ }^{\circ} \mathrm{C}$ for $3 \mathrm{~d}$. Yellow block crystals were obtained when the mixture was cooled to room temperature. Yield: $c a$. $56 \%$ based on Cd. Calcd. for $\mathrm{C}_{26} \mathrm{H}_{14} \mathrm{CdN}_{2} \mathrm{O}_{9}(\%)$ : C, 51.13; H, 2.31; N, 4.59. Found (\%): C, 50.42; H, 2.38; N, 4.69. IR ( $\mathrm{KBr}$ pellet, $\mathrm{cm}^{-1}$ ): $3488 \mathrm{~m}, 1743 \mathrm{~s}$, $1625 \mathrm{~m}, 1593 \mathrm{~m}, 1549 \mathrm{~s}, 1372 \mathrm{~s}, 1294 \mathrm{~s}, 1186 \mathrm{~s}, 1091 \mathrm{~s}, 1014 \mathrm{~m}$, $805 \mathrm{~m}, 766 \mathrm{~m}, 696 \mathrm{~m}, 652 \mathrm{w}, 576 \mathrm{w}, 525 \mathrm{w}$.

2.2.2 Synthesis of $\left.\left\{\left[\mathrm{Cd}_{2} \text { (dbta) (phen) }\right)_{2}\left(\mathrm{H}_{2} \mathrm{O}\right)\right] \cdot \mathrm{H}_{2} \mathrm{O}\right\}_{n}$ (2). The preparation of $\mathbf{2}$ was similar to that of $\mathbf{1}$ except that phen $(0.0099 \mathrm{~g}, 0.05 \mathrm{mmol})$ was used instead of $2,2^{\prime}$-bpy ( $0.0078 \mathrm{~g}$, $0.05 \mathrm{mmol}$ ). Yellow block crystals were obtained. Yield: $c a .62 \%$ based on Cd. Calcd. for $\mathrm{C}_{40} \mathrm{H}_{24} \mathrm{Cd}_{2} \mathrm{~N}_{6} \mathrm{O}_{14}$ (\%): C, 46.31; H, 2.33; N, 8.10. Found (\%): C, 45.59; H, 2.35; N, 8.21. IR (KBr pellet, $\mathrm{cm}^{-1}$ ): $3488 \mathrm{w}, 3068 \mathrm{w}, 2362 \mathrm{w}, 1599 \mathrm{w}, 1561 \mathrm{w}, 1523 \mathrm{~m}$, $1434 \mathrm{~m}, 1389 \mathrm{~m}, 1338 \mathrm{~s}, 1097 \mathrm{w}, 932 \mathrm{~m}, 925 \mathrm{w}, 843 \mathrm{~s}, 728 \mathrm{~s}, 785$ m, $716 \mathrm{~s}, 626 \mathrm{w}, 544 \mathrm{w}, 423 \mathrm{w}$.

2.2.3 Synthesis of $\left\{\left[\mathrm{Cu}_{2} \text { (dbta) }\left(2,2^{\prime}-\text { bpy }\right)_{2}\right] \cdot \mathrm{H}_{2} \mathrm{O}\right\}_{n}$ (3). The preparation of $\mathbf{3}$ was similar to that of $\mathbf{1}$ except that $\mathrm{CuO}$ $(0.0080 \mathrm{~g}, 0.1 \mathrm{mmol})$ was used instead of $\mathrm{CdO}(0.0064 \mathrm{~g}, 0.05$ mmol). Blue plate block crystals were obtained. Yield: ca. $45 \%$ based on $\mathrm{Cu}$. Calcd. for $\mathrm{C}_{36} \mathrm{H}_{22} \mathrm{Cu}_{2} \mathrm{~N}_{6} \mathrm{O}_{13}$ (\%): C, 49.49; $\mathrm{H}$, 2.54; N, 9.62. Found (\%): C, 49.71; H, 2.42; N, 9.21. IR ( $\mathrm{KBr}$ pellet, $\mathrm{cm}^{-1}$ ): $3434 \mathrm{~m}, 1620 \mathrm{~s}, 1593 \mathrm{~m}, 1536 \mathrm{~s}, 1441 \mathrm{~m}, 1390 \mathrm{~m}$, $1328 \mathrm{~s}, 1098 \mathrm{w}, 761 \mathrm{~m}, 717 \mathrm{~m}, 627 \mathrm{w}, 515 \mathrm{w}, 414 \mathrm{w}$.

\subsection{X-ray data collection and structure determination}

Intensity data were collected on a Bruker Smart APEX II CCD diffractometer equipped with graphite-monochromated Mo-K $\alpha$ radiation $(\lambda=0.71073 \AA)$ using $\omega-\varphi$ scan mode. A semiempirical absorption correction was applied using the SADABS program. ${ }^{43}$ The structure was solved with direct methods and refined by full-matrix least-squares on $F^{2}$ using the SHELXS-2014/7 and SHELXL-2014/7 programs, respectively. ${ }^{44,45}$ Non-hydrogen atoms were refined anisotropically and hydrogen atoms were placed in the geometrically calculated positions. The $(\mathrm{dbta})^{4-}$ anions and lattice water molecules in 3 were 
disordered and refined with different occupancy ratios. The hydrogen atoms of the disordered lattice water molecules in 3 were not added. The crystallographic data and selected bonds and angles for 1-3 are given in Tables S1 and S2, $\dagger$ respectively.

\section{Results and discussion}

\subsection{Syntheses and characterization}

The hydrothermal reactions of CdO and 6,6'-dinitro-2,2',4,4'biphenyltetracarboxylic acid $\left(\mathrm{H}_{4} \mathrm{dbta}\right)$ with $2,2^{\prime}$-bpy gave the $3 \mathrm{D}$ framework of $\mathbf{1}$. To explore the influencing factors and formation mechanism for the in situ reaction of $\mathrm{H}_{4} \mathrm{dbta}$ in $\mathbf{1}$, compounds 2 and 3 were synthesized under hydrothermal conditions (Scheme 3). When N-donor phen/dpe ligands were used instead of $2,2^{\prime}$-bpy in 1 , a structurally different $1 \mathrm{D}$ chain/ 3D pillared bilayer framework was formed in 2 and $\left[\mathrm{Cd}_{2}\right.$ (dbta) (dpe) $]_{n}{ }^{40}$ under similar reaction conditions. Similarly, the replacement of $\mathrm{Cd}$ (II) ions in $\mathbf{1}$ by $\mathrm{Cu}$ (II)/Zn(II) resulted in two different 2D network/3D "brick-wall" frameworks. ${ }^{37}$ Apparently, the in situ reaction of $\mathrm{H}_{4} \mathrm{dbta}$ to $\mathrm{H}_{2} \mathrm{ddpa}$ did not occur for compounds 2 and 3 , which suggests that the metal ions and $\mathrm{N}$ donor ligands have great effect on the in situ reaction.

For compounds 1-3, the elemental analyses were consistent with their chemical formulae. PXRD showed that the observed patterns for $\mathbf{1}$ and $\mathbf{2}$ correlate well with the simulated patterns generated from the single-crystal X-ray diffraction data (Fig. S2 and S3,†). In the IR spectra of 1-3 (Fig. S4, $\dagger$ ), the absence of any strong bands around $1700 \mathrm{~cm}^{-1}$ indicates that all the carboxylic groups are depronated. For 1, a sharp absorption band at $1743 \mathrm{~cm}^{-1}$ is observed, confirming the existence of the $\nu_{\mathrm{C}=\mathrm{O}}$ group. The absorption bands at 1372 and $1186 \mathrm{~cm}^{-1}$ for 1 can be assigned to the vibrations of $\nu_{\mathrm{C}-\mathrm{O}-\mathrm{C}}^{\mathrm{as}}$ and $\nu_{\mathrm{C}-\mathrm{O}-\mathrm{C}}^{\mathrm{s}}$ groups, respectively. Thermal stability studies (Fig. S5, $\dagger$ ) demonstrate that $\mathbf{1}$ is thermally stable up to $250^{\circ} \mathrm{C}$; then, a quick weight loss (ca. 55\%) from 250 to $360{ }^{\circ} \mathrm{C}$ is observed, which is caused by the decomposition of ligands. For 2, weight loss of about $3.6 \%$ is observed from 25 to $166{ }^{\circ} \mathrm{C}$, which is ascribed to the release of lattice and coordinated water, followed by a quick weight loss of about $65.6 \%$ from 285 to $373{ }^{\circ} \mathrm{C}$. For 3, weight loss of about $2.2 \%$ is observed from 25 to $117^{\circ} \mathrm{C}$, which may be ascribed to the release of lattice water; this is followed a quick weight loss of about $47.8 \%$ from 225 to $276{ }^{\circ} \mathrm{C}$. The second step of the weight loss for $\mathbf{2}$ and $\mathbf{3}$ is caused by the decomposition of the ligands.

\subsection{Structural descriptions}

3.2.1 $\left\{\left[\mathbf{C d} \text { (ddpa) }\left(2,2^{\prime} \text {-bpy) }\right] \cdot \mathbf{H}_{2} \mathbf{O}\right\}_{n}(\mathbf{1})\right.$. The X-ray analysis reveals that 1 crystallizes in the space group $C 2 / c$ and has a 3D framework containing a 1D inorganic chain $(-\mathrm{Cd}-\mathrm{O}-\mathrm{C}-\mathrm{O}-\mathrm{Cd}-)$. As shown in Fig. 1a, each asymmetric unit of 1 contains one $\mathrm{Cd}(\mathrm{II})$ ion, one $\mathrm{ddpa}^{2-}$ ligand, one 2,2'-bpy ligand and one lattice $\mathrm{H}_{2} \mathrm{O}$ molecule. The $\mathrm{Cd}(\mathrm{II})$ ion is coordinated by four oxygen atoms from four different $\mathrm{ddpa}^{2-}$ ligands and two nitrogen atoms from one 2,2'-bpy ligand to furnish distorted octahedral coordination geometry. All the $\mathrm{Cd}-\mathrm{O}$ and $\mathrm{Cd}-\mathrm{N}$ bond lengths are in accordance with those reported in other related ref. 46 and 47 The two carboxyl groups in each $\mathrm{ddpa}^{2-}$ ligand adopt

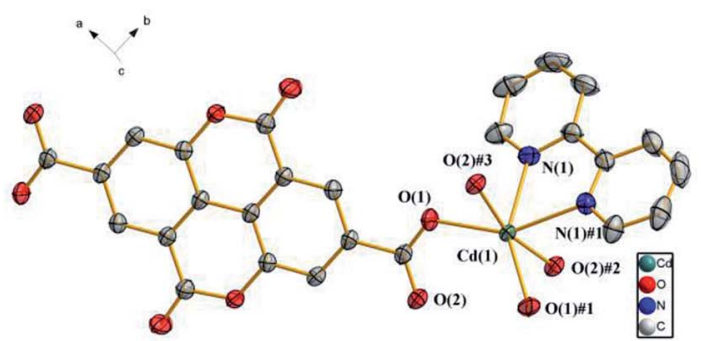

(a)

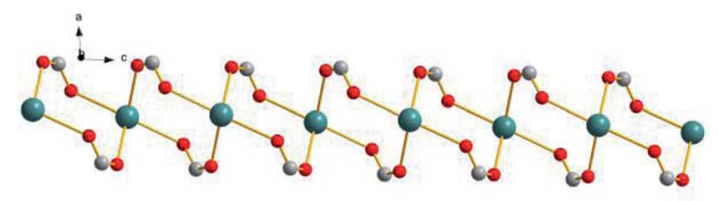

(b)

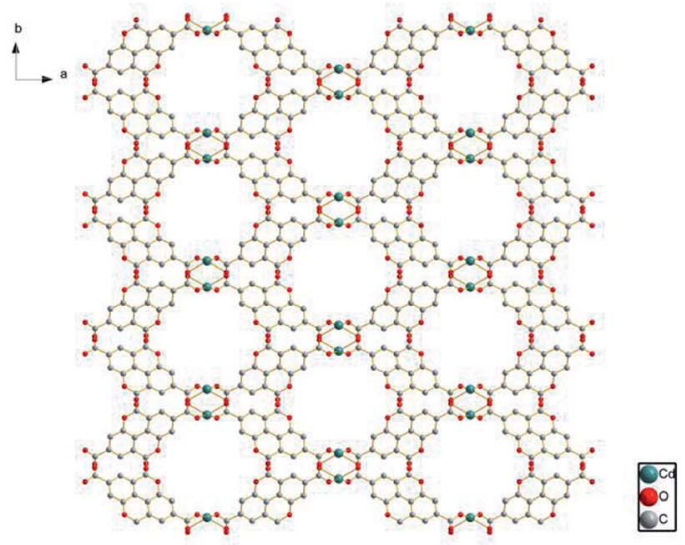

(c)

Fig. 1 (a) The coordination environments of $\mathrm{Cd}(\Perp)$ ions in 1 , symmetry codes: \#1: $-x, y,-z+1 / 2$; \#2: $-x,-y,-z+1$; \#3: $x,-y, z-1 / 2$. All hydrogen atoms are omitted for clarity. (b) The $1 \mathrm{D}$ chain $(-\mathrm{Cd}-\mathrm{O}-\mathrm{C}-$ $\mathrm{O}-\mathrm{Cd}-$ ) in 1. (c) The 3D framework assembled from the 1D chains. The $2,2^{\prime}$-bpy molecules, lattice water and hydrogen atoms are omitted for clarity.

a $\mu^{2}-\eta^{1}: \eta^{1}$ coordination mode to connect the adjacent Cd(II) ions and generate a 1D inorganic chain (-Cd-O-C-O-Cd-) (Fig. 1b). In the $1 \mathrm{D}$ chains formed by dinuclear rings, the $\mathrm{Cd}(\mathrm{II}) \cdots \mathrm{Cd}(\mathrm{II})$ distance is 4.3658(2) A. Along the $c$ axis, such a chain is further linked by ddpa ${ }^{2-}$ ligands to generate a 3D framework structure (Fig. 1c). The whole framework has octagonal-prism-like 1D channels filled with $2,2^{\prime}$-bpy ligands and lattice $\mathrm{H}_{2} \mathrm{O}$ molecules, and the effective solvent accessible volume is $147 \AA^{3}$ per unit cell ( $6.4 \%$ of the total cell volume calculated by the Platon program).

3.2.2 $\left.\left\{\left[\mathrm{Cd}_{2} \text { (dbta) (phen) }\right)_{2}\left(\mathrm{H}_{2} \mathrm{O}\right)\right] \cdot \mathbf{H}_{2} \mathrm{O}\right\}_{n}$ (2). To further examine the influence of the $\mathrm{N}$-donor ligands on the structure of $\mathbf{1}$, a larger sized aromatic chelate ligand phen is used instead of 2,2'-bpy. Consequently, compound 2 , which features a 1D looped chain, is obtained. Compound 2 crystallizes in the triclinic space group $P \overline{1}$. In the asymmetric unit, there exist two crystallographically unique $\mathrm{Cd}(\mathrm{II})$ ions, one $\mathrm{dbta}^{4-}$ ligand, two 


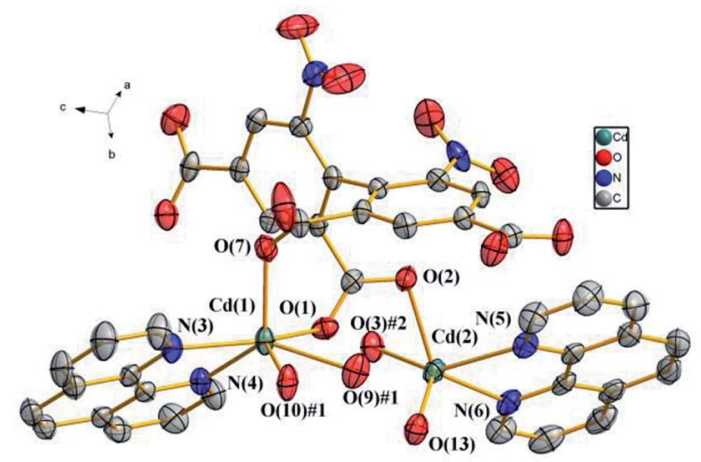

(a)

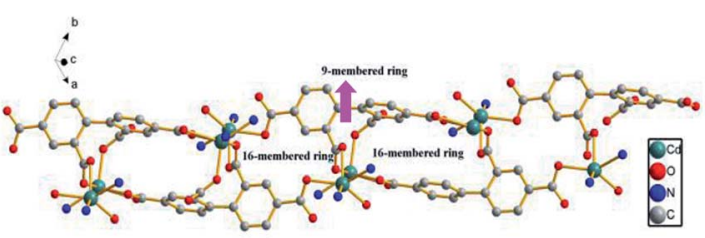

(b)

Fig. 2 (a) The coordination environments of $\mathrm{Cd}(॥)$ ions in 2, symmetry codes: \#1: $-x, y,-z+1 / 2$; \#2: $-x,-y,-z+1$; \#3: $x,-y, z-1 / 2$. All hydrogen atoms are omitted for clarity. (b) The 1D looped chain in 2. The phen ligands, nitro groups and hydrogen atoms are omitted for clarity.

phen ligands, one coordinated $\mathrm{H}_{2} \mathrm{O}$ molecule and one lattice $\mathrm{H}_{2} \mathrm{O}$. As illustrated in Fig. 2a, the Cd (1) ion exhibits distorted octahedral geometry and is coordinated by two nitrogen atoms from a chelate phen and four oxygen atoms from three carboxylic groups of two $\mathrm{dbta}^{4-}$ ligands. The $\mathrm{Cd}(2)$ ion is ligated by two nitrogen atoms from a chelate phen, one oxygen atom from one coordinated $\mathrm{H}_{2} \mathrm{O}$ molecule and two oxygen atoms from two $\mathrm{dbta}^{4-}$ ligands to form distorted tetragonal pyramid geometry. These bond lengths are similar to those found in related dicadmium-tetracarboxylate polymers. ${ }^{37}$ The four carboxylate groups of the $\mathrm{dbta}^{4-}$ ligands adopt three different coordination modes, i.e., monodentate, chelating bidentate and bridging bidentate to generate a 1D looped chain containing a 16-membered ring and a 9-membered ring (Fig. 2b).

3.2.3 $\left\{\left[\mathrm{Cu}_{2}(\mathbf{d b t a})(2,2 \text { '-bpy })_{2}\right] \cdot \mathbf{H}_{2} \mathbf{O}\right\}_{n}$ (3). To further explore the influence of metal ions on the structure of $\mathbf{1}, \mathrm{Cu}$ (II) ion is used instead of $\mathrm{Cd}$ (II) ion. Consequently, compound 3, which features a 2D network, is obtained. Compound 3 crystallizes in the triclinic space group $P \overline{1}$. In the asymmetric unit, there exist two crystallographically unique $\mathrm{Cu}(\mathrm{II})$ ions, one $\mathrm{dbta}^{4-}$ ligand, two 2,2'-bpy ligands and one free $\mathrm{H}_{2} \mathrm{O}$ molecule. As illustrated in Fig. 3a, $\mathrm{Cu}$ (1) and $\mathrm{Cu}$ (2) ions exhibit distorted square geometry and are coordinated by two nitrogen atoms from a chelate 2,2'-bpy and two oxygen atoms from two carboxylic groups of two $\mathrm{dbta}^{4-}$ ligands. The four carboxylate groups of $\mathrm{dbta}^{4-}$ ligands adopt monodentate coordination modes. Each $\mathrm{Cu}(\mathrm{II})$ ion is bridged by $\mathrm{dbta}^{4-}$ ligands to form a $2 \mathrm{D}$ convexshaped network extending along the $a b$ plane (Fig. $3 \mathrm{~b}$ ).

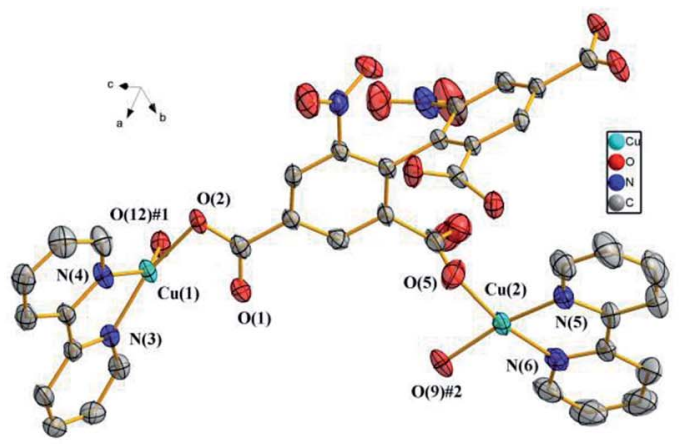

(a)

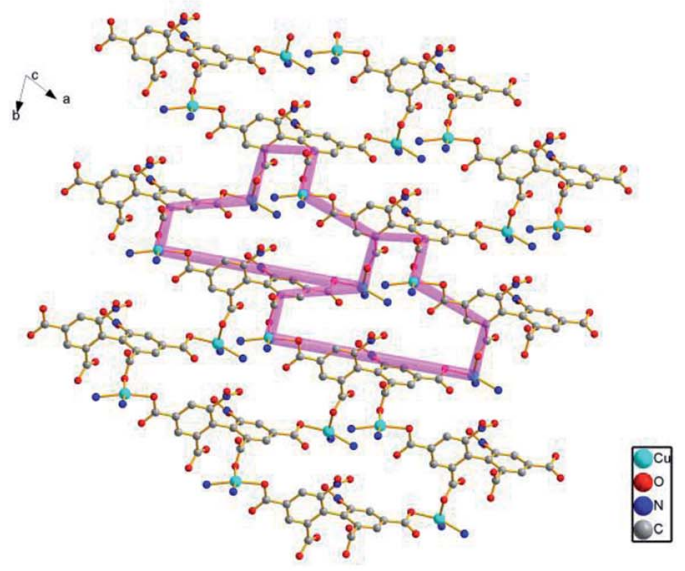

(b)

Fig. 3 (a) The coordination environments of $\mathrm{Cu}(॥)$ ions in 3, symmetry codes: \#1: $-x, y,-z+1 / 2$; \#2: $-x,-y,-z+1$; \#3: $x,-y, z-1 / 2$. All hydrogen atoms are omitted for clarity. (b) The 2D convex-shaped network in 2 . The $2,2^{\prime}$-bpy molecules and hydrogen atoms are omitted for clarity.

\subsection{Influencing factors and mechanism for the in situ generation of $\mathrm{ddpa}^{2-}$}

To evaluate whether both $2,2^{\prime}$-bpy and Cd(II) ions play crucial roles in the reaction process, after replacing $2,2^{\prime}$-bpy by phen/ dpe ligands, the 1D looped chain/3D pillared bilayer framework was formed in 2 and $\left[\mathrm{Cd}_{2} \text { (dbta) (dpe) }\right]_{n}{ }^{40}$ under similar reaction conditions, respectively. Compound 2 and $\left[\mathrm{Cd}_{2}(\mathrm{dbta})\right.$ $(\mathrm{dpe})]_{n}$ contain no ddpa ${ }^{2-}$ ligand, suggesting that the in situ reaction may be prohibited. To further explore this interesting phenomenon, $\mathrm{Cu}$ (II) ion/Zn(II) is used instead of $\mathrm{Cd}$ (II) ion, followed by the same procedure as that for 1 . The $2 \mathrm{D}$ network of 3 and the $3 \mathrm{D}$ "brick-wall" framework ${ }^{37}$ were obtained as new phases, indicating that $\mathrm{Cu}$ (II)/Zn(II) anions have the same negative effect on the in situ reaction as phen/dpe. Therefore, it can be concluded that the in situ reaction of the dbta ${ }^{4-}$ ligand resulted from synergetic effects of both $2,2^{\prime}$-bpy and $\mathrm{Cd}(\mathrm{II})$ ions under hydrothermal conditions. This phenomenon is greatly different from the in situ generation of $\mathrm{ddpa}^{2-}$ within the $\mathrm{Ni}(\mathrm{II}) /$ Ce(III) reaction system. ${ }^{\mathbf{4 1 , 4 2}}$

The possible mechanism for the in situ generation of ddpa ${ }^{2-}$ was postulated and displayed in Scheme 4. An intramolecular nucleophilic aromatic substitution reaction (SNAr) may have 


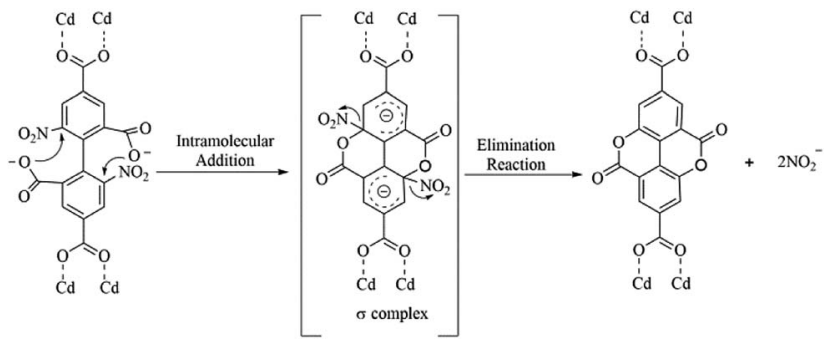

Scheme 4 The possible mechanism for in situ generation of $\mathrm{ddpa}^{2-}$.

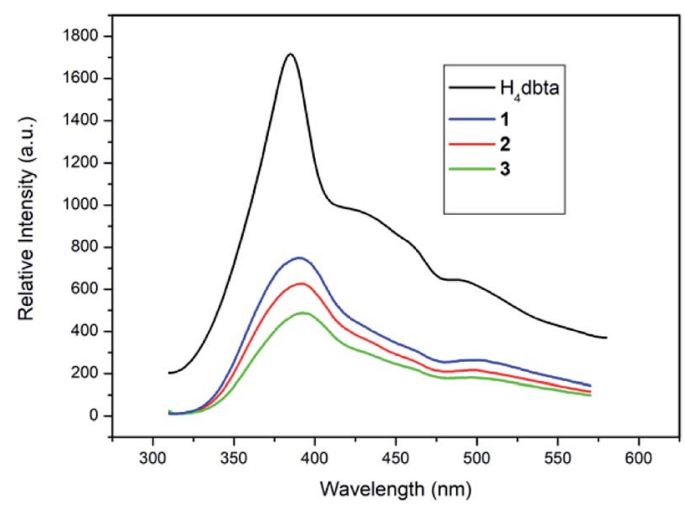

Fig. 4 The emission spectra of free $\mathrm{H}_{4} \mathrm{dbta}$ and $1-3$ in the solid state at room temperature.

occurred during hydrothermal synthesis processes. As shown in Scheme 4, the protonated carboxyl groups serve as nucleophilic agents to form the $\sigma$-complex intermediate (addition reaction), which can generate the cyclization products by eliminating the nitroso-group (elimination reaction). To illustrate the above plausible mechanism, several drops of $\mathrm{AgNO}_{3}$ solution (0.1 $\left.\mathrm{mol} \mathrm{L}^{-1}\right)$ were added into the filtrate of the reaction mixture, and a large faint yellow precipitate was formed immediately, which revealed that $\mathrm{AgNO}_{2}$ might be formed. The clarification of the mechanism for internal esterifications as well as the origin of the synergy between 2, 2'-bpy and Cd(II) ion under hydrothermal conditions requires further studies, which are currently underway in our laboratory.

\subsection{Photoluminescent properties}

The solid state luminescence of free $\mathrm{H}_{4} \mathrm{dbta}$ and 1-3 was investigated at room temperature (Fig. 4). Upon excitation at $296 \mathrm{~nm}$, the free $\mathrm{H}_{4} \mathrm{dbta}$ exhibits intense emission at $384 \mathrm{~nm}$. Compounds 1-3 exhibited photoluminescence with emission maxima at $390 \mathrm{~nm}$ (1 and 2) and $393 \mathrm{~nm}$ (3), respectively. The three compounds exhibit a red-shift compared with the free $\mathrm{H}_{4} \mathrm{dbta}$ ligand. Compounds 1-3 exhibit similar emission peaks to the free $\mathrm{H}_{4} \mathrm{dbta}$ ligand. We tentatively assign them to intraligand photoluminescence. ${ }^{48,49}$ The different red-shifts and intensities of the emission of three compounds compared to that of the free $\mathrm{H}_{4} \mathrm{dbta}$ ligand may result from the differences in the coordination environments and different structures and in situ ligands.

\section{Conclusions}

In summary, a novel 3D Cd(II) coordination polymer is hydrothermally synthesized in situ, and the influencing factors and mechanism for the in situ reaction are briefly discussed. The formation of 1 suggests that the in situ reaction for the $\mathrm{dbta}^{4-}$ ligand resulted from synergetic effects of both 2,2'-bpy and Cd(II) ion under hydrothermal conditions. A study of the mechanism indicates that an intramolecular nucleophilic aromatic substitution reaction (SNAr) may have occurred during hydrothermal synthesis processes. The study also reveals that $\mathrm{C}-\mathrm{O}$ ester bonds can also be formed in situ by $\mathrm{H}_{4} \mathrm{dbta}$, which provides a promising route to design and construct a new organic ligand with special structures and properties. In the future, we will further clarify the mechanism for the internal esterifications as well as the origin of the synergy between 2,2'-bpy and Cd(II) ions under hydrothermal conditions.

\section{Conflicts of interest}

There are no conflicts to declare.

\section{Acknowledgements}

This work was financially supported by the NSF of China (No. 21373178, 21663031 and 21503183), which are gratefully acknowledged.

\section{References}

1 X. M. Zhang, Coord. Chem. Rev., 2005, 249, 1201-1219.

2 X. M. Chen and M. L. Tong, Acc. Chem. Res., 2007, 40, 162170.

3 Y. C. Chang and S. L. Wang, J. Am. Chem. Soc., 2012, 134, 9848-9851.

4 E. T. Nguyen, X. Zhao, D. Ta, P. L. Nguyen and X. H. Bu, Cryst. Growth Des., 2015, 15, 5939-5944.

5 T. Huang, Y. L. Wang, Q. Yin, B. Karadeniz, H. F. Li, J. Lü and R. Cao, CrystEngComm, 2016, 18, 2742-2747.

6 G. B. Li, J. M. Liu, Z. Q. Yu, W. Wang and C. Y. Su, Inorg. Chem., 2009, 48, 8659-8661.

7 A. K. Ghosh, T. S. Mahapatra, R. Clérac, C. Mathonière, V. Bertolasi and D. Ray, Inorg. Chem., 2015, 54, 5136-5138.

8 C. E. Rowland, N. Belai, K. E. Knope and C. L. Cahill, Cryst. Growth Des., 2010, 15, 1390-1398.

9 P. Kanoo, R. Matsuda, H. Sato, L. C. Li, H. J. Jeon and S. Kitagawa, Inorg. Chem., 2013, 52, 10735-10737.

10 X. M. Zhang, J. J. Hou and H. S. Wu, Dalton Trans., 2004, 3437-3439.

11 F. L. Yang, J. Tao, R. B. Huang and L. S. Zheng, Inorg. Chem., 2011, 50, 911-917.

12 D. Wu, X. J. Bai, H. R. Tian, W. T. Yang, Z. W. Li, Q. Huang, S. Y. Du and Z. M. Sun, Inorg. Chem., 2015, 54, 8617-8624.

13 L. Sun, L. Ma, J. B. Cai, L. Liang and H. Deng, CrystEngComm, 2012, 14, 890-898. 
14 R. T. Dong, Z. Y. Ma, L. X. Chen, L. F. Huang, Q. H. Li, M. Y. Hu, M. Y. Shen, C. W. Li and H. Deng, CrystEngComm, 2015, 17, 5814-5831.

15 C. C. Chang, Y. C. Huang, S. M. Huang, J. Y. Wu, Y. H. Liu and K. L. Lu, Cryst. Growth Des., 2012, 12, 3825-3828.

16 M. A. Nadeem, M. Bhadbhade, R. Bircher and J. A. Stride, Cryst. Growth Des., 2010, 10, 4060-4067.

17 W. Q. Zhang, W. Y. Zhang, R. D. Wang, C. Y. Ren, Q. Q. Li, Y. P. Fan, B. Liu, P. Liu and Y. Y. Wang, Cryst. Growth Des., 2017, 17, 517-526.

18 B. Liu, L. Wei, N. N. Li, W. P. Wu, H. Miao, Y. Y. Wang and Q. Z. Shi, Cryst. Growth Des., 2014, 14, 1110-1127.

19 Y. P. He, L. B. Yuan, H. Xu and J. Zhang, Cryst. Growth Des., 2017, 17, 290-294.

20 H. Wang, G. J. Xing, F. Chen, J. Sun and Y. H. Zhang, Chin. J. Struct. Chem., 2015, 34, 1113-1120.

21 L. Qin, J. S. Hu, Y. Z. Li and H. G. Zheng, Cryst. Growth Des., 2012, 12, 403-413.

22 J. J. Liu, Y. F. Guan, M. J. Lin, C. C. Huang and W. X. Dai, Cryst. Growth Des., 2016, 16, 2836-2842.

23 E. Lee, H. Ju, S. Kim, K. M. Park and S. S Lee, Cryst. Growth Des., 2015, 15, 5427-5436.

24 B. Hu, T. Tao, Z. Y. Bin, Y. X. Peng, B. B. Ma and W. Huang, Cryst. Growth Des., 2014, 14, 300-309.

25 T. T. Jia, S. R. Zhu, M. Shao, Y. M. Zhao and M. X. Li, Inorg. Chem. Commun., 2008, 11, 1221-1223.

26 L. L. Wen, F. Wang, X. K. Leng, C. G. Wang, L. Y. Wang, J. M. Gong and D. F. Li, Cryst. Growth Des., 2010, 10, 28352838.

27 L. Cheng, S. H. Gou and J. Q. Wang, J. Mol. Struct., 2011, 991, 149-157.

28 J. J. Wang, T. T. Wang, L. Tang, X. Y. Hou, L. J. Gao, F. Fu and M. L. Zhang, J. Coord. Chem., 2013, 66, 3979-3988.

29 J. Jia, M. Shao, T. T. Jia, S. R. Zhu, Y. M. Zhao, F. F. Xing and M. X. Li, CrystEngComm, 2010, 12, 1548-1561.

30 W. X. Chen, H. R. Xu, G. L. Zhuang, L. S. Long, R. B. Huang and L. S. Zheng, Chem. Commun., 2011, 47, 11933-11935.

31 Y. H. Su, F. Luo, H. Li, Y. X. Che and J. M. Zheng, CrystEngComm, 2011, 13, 44-46.
32 Z. R. Pan, J. Xu, Xi. Q. Yao, Y. Z. Li, Z. J. Guo and H. G. Zheng, CrystEngComm, 2011, 13, 1617-1624.

33 H. Tian, K. Wang, Q. X. Jia, Q. Sun, Y. Ma and E. Q. Gao, Cryst. Growth Des., 2011, 11, 5167-5170.

34 F. Su, L. P. Lu and S. S. Feng, J. Mol.Struct., 2015, 1096, 38-42.

35 F. Su, L. P. Lu, S. S. Feng, M. L. Zhu, Z. Q. Gao and Y. H. Dong, Dalton Trans., 2015, 44, 7213-7222.

36 C. Y. Ren, B. Liu, W. P. Wu, P. Liu, G. P. Yang, Y. F. Kang and Y. Y. Wang, Inorg. Chem. Commun., 2015, 53, 46-49.

37 Q. Q. Li, W. Q. Zhang, C. Y. Ren, Y. P. Fan, J. L. Li, P. Liu and Y. Y. Wang, CrystEngComm, 2016, 18, 3358-3371.

38 W. Q. Zhang, W. Y. Zhang, R. D. Wang, C. Y. Ren, Q. Q. Li, Y. P. Fan, B. Liu, P. Liu and Y. Y. Wang, Cryst. Growth Des., 2017, 17, 517-526.

39 J. Y. Zhang, X. H. Jing, Y. Ma, A. L. Cheng and E. Q. Gao, Cryst. Growth Des., 2011, 11, 3681-3685.

40 J. W. Wang, Y. C. Su and J. J. Wang, Chin. J. Struct. Chem., 2015, 34, 1385-1390.

41 R. K. Feller, P. M. Forster, F. Wudl and A. K. Cheetham, Inorg. Chem., 2007, 46, 8717-8721.

42 X. Y. Cao, L. Q. Yu and R. D. Huang, J. Solid State Chem., 2014, 210, 74-78.

43 G. M. Sheldrick, SADABS, A Program for Empirical Absorption Correction of Area detector Data, University of Göttingen, Germany 1997.

44 G. M. Sheldrick, SHELXS-2014/7, Program for Crystal Structure Solution, University of Göttingen, Germany 2014.

45 G. M. Sheldrick, SHELXL-2014/7, Program for Crystal Structure Refinement, University of Göttingen, Germany 2014.

46 J. J. Wang, M. L. Yang, H. M. Hua, G. L. Xue, D. S. Li and Q. Z. Shi, Z. Anorg. Allg. Chem., 2007, 633, 341-345.

47 L. L. Liu, C. X. Yu, Y. R. Li, J. J. Han, F. J. Ma and L. F. Ma, CrystEngComm, 2015, 17, 653-664.

48 C. C. Du, X. F. Wang, S. B. Zhou, D. Z. Wang and D. Z. Jia, CrystEngComm, 2017, 19, 6758-6777.

49 D. Chisca, L. Croitor, O. Petuhov, O. V. Kulikova, G. F. Volodina, E. B. Coropceanu, A. E. Masunov and M. S. Fonari, CrystEngComm, 2018, 20, 432-447. 